\title{
ACCURACY OF REFERENCES IN THE ORTHOPAEDIC LITERATURE
}

\author{
A. G. Sutherland, N. Craig, N. Maffulli, A. Brooksbank, J. S. Moir \\ From the University of Aberdeen, Scotland
}

The accuracy of reference lists in scientific papers is important. Inaccuracy reflects both upon the paper and its authors, and the journal in which the article is published. The reader must be able to retrieve the original of any reference cited in support of a point made, in order to assess independently the validity of the latter. Similarly, the reader wishing to read more widely on a subject mentioned in a paper may use the reference list as a guide. In this case, the reference must be accurate so that the reader can decide whether it is to be sought and read. The author of a paper has a moral duty to ensure the accuracy of citations as well as the validity and scientific rigour of his or her own work. ${ }^{1}$

Although several specialties have audited the accuracy of references cited in their journals, ${ }^{2-7}$ we are not aware of such a review of the orthopaedic literature. We have examined four major orthopaedic journals, the British and American editions of the Journal of Bone and Joint Surgery, Clinical Orthopaedics and Related Research and Acta Orthopaedica Scandinavica, for inaccuracies in the listed references, and assessed the potential impact of any such errors found.

\section{Materials and Methods}

We examined all the issues of the Journal of Bone and Joint Surgery [British], the Journal of Bone and Joint Surgery [American] (volumes 67-B, 67-A, 77-B and 77-A) and Clinical Orthopaedics and Related Research from 1985 and 1995 and of Acta Orthopaedica Scandinavica

A. G. Sutherland, FRCS Ed, Specialist Registrar in Orthopaedics N. Craig, FRCS Ed, Specialist Registrar in Orthopaedics

N. Maffulli, PhD, FRCS Orth, Senior Lecturer and Consultant in Orthopaedic Surgery

Department of Orthopaedic Surgery, University of Aberdeen, Polwarth Building, Foresterhill, Aberdeen AB25 2ZD, UK.

A. Brooksbank, FRCS Ed, Specialist Registrar in Orthopaedics Department of Orthopaedics, Dundee University, Ninewells Hospital, Dundee DD1 9SY, UK.

J. S. Moir, ChM, FRCS Orth, Consultant Orthopaedic Surgeon Department of Orthpaedics, Western Infirmary, Dumbarton Road, Glasgow G11 6NT, UK.

Correspondence should be sent to $\mathrm{Mr}$ N. Maffulli.

(C)2000 British Editorial Society of Bone and Joint Surgery 0301-620X/00/19035\$2.00

J Bone Joint Surg [Br] 2000;82-B:9-10.

VOL. 82-B, No. 1, JANUARY 2000 from 1985 and 1994 (volumes 55 and 64). The University of Aberdeen Medical School Library was unable to obtain some issues of Acta Orthopaedica Scandinavica between 1995 and 1996 and therefore their collection was incomplete. All references from each volume of the above journals were numbered sequentially. A sample of 100 reference citations was then selected using the randomnumber generator function of Microsoft Excel 97 (Office 97; Microsoft Corporation, Seattle, Washington). When the reference quoted was a book, a further random number was taken, but no attempt was made to exclude proceedings of scientific meetings or journals not found in Index Medicus. The original of each reference was sought in the University Medical School Library, or by interlibrary loan if it was not held by the library. Each reference was then checked against the original paper with regard to the accuracy of authors, title, journal, year, volume and page numbers.

Errors were graded as grade I if there was little or no impact on the value of the reference, grade II if the error detracted significantly from the value of the reference, and grade III if a quoted paper could not be found as cited. Table I shows examples of errors in each grade found in our study.

\section{Results}

Table II summarises the results from the two volumes of each of the four journals examined. The British and American volumes of the Journal of Bone and Joint Surgery both had a consistently low number of errors, with none in grade III. Clinical Orthopaedics and Related Research had high levels of errors (37\% in 1985, falling to $31 \%$ in 1995), with several grade-III errors ( $8 \%$ and $2 \%$, respectively). By contrast, Acta Orthopaedica Scandinavica had a high level of error (20\%) in 1985, with four grade-III errors, but by 1994 had achieved a marked improvement, with a level of error of $3 \%$. The 100 checked references represent small samples of each journal, but yield a level of error of between $3 \%$ and $37 \%$. An increase in the number of reference citations is noted in each journal, with the exception of Clinical Orthopaedics and Related Research between 1985 and 1994-1995, the most marked increase being in the American volume of the Journal of Bone and Joint Surgery. 
Table I. Examples of errors and their grading

\begin{tabular}{lll}
\hline Grade I & Grade II & Grade III \\
\hline Author initials & Missing subtitle & Reference not found as quoted - \\
Missing author & Missing page number (first or last) & volume/page numbers refer \\
Journal abbreviation & Wrong page number & to a different paper \\
Spelling mistake & Inaccurate title & \\
\hline
\end{tabular}

Table II. Errors found in the references quoted

\begin{tabular}{lcccccc}
\hline Journal & Year & $\begin{array}{l}\text { Number of } \\
\text { references }\end{array}$ & $\begin{array}{l}\text { Grade-1 } \\
\text { errors }\end{array}$ & $\begin{array}{l}\text { Grade-II } \\
\text { errors }\end{array}$ & $\begin{array}{l}\text { Grade-III } \\
\text { errors }\end{array}$ & $\begin{array}{l}\text { Total } \\
\text { errors }\end{array}$ \\
\hline J Bone Joint Surg $[\mathrm{Br}]$ & 1985 & 2417 & 2 & 2 & & 4 \\
& 1995 & 3758 & 4 & 5 & & 9 \\
J Bone Joint Surg [Am] & 1985 & 4584 & 3 & 3 & & 6 \\
& 1995 & 8450 & 9 & 3 & & 12 \\
Acta Orthop Scand & 1985 & 1611 & 2 & 14 & 4 & 20 \\
& 1994 & 2328 & 1 & 2 & & 3 \\
Clin Orthop Rel Res & 1985 & 10463 & 13 & 16 & 8 & 37 \\
& 1995 & 8683 & 15 & 14 & 2 & 31 \\
\hline
\end{tabular}

\section{Discussion}

The list of references in a paper published in the medical literature must be accurate. Failure to achieve this may lead the reader to doubt the value of a cited paper if, for instance, the title is incomplete. A previous study ${ }^{2}$ examined only journals quoted in Index Medicus, but, if a reference is cited, it must be accurate, regardless of the journal in which it is published. Index Medicus has also been suggested as a bench-mark for accuracy of citation, ${ }^{8}$ but this is not without potential error. Indeed, the senior author (NM) appears in Index Medicus under three different spellings, Maffuli N, Maffulli V, and Maffulli N, the last being correct.

Not all clinicians have a large library at their disposal; a missing last page on the reference may make a request for an interlibrary loan difficult to fulfil. In extreme cases, it may be impossible to locate the quoted reference, severely weakening a point made in a paper which it supports. Less major errors, such as missing author initials or a wrong spelling, do not devalue the reference greatly, but they do reflect a lack of attention to detail.

Previous studies of journals of biomedical science ${ }^{2-7}$ have found overall rates of error of between $8 \%$ and $65 \%$, but did not examine the severity of these inaccuracies or their impact on the reader. Most errors found in our study have been minor (grade I) or moderate (grade II), while Acta Orthopaedica Scandinavica and Clinical Orthopaedics and Related Research contained the only severe (grade-III) mistakes.

Authors have a moral duty to read cited references in full and to ensure their accuracy and relevance ${ }^{1}$ but editors also strive for high standards of accuracy, in both submitted manuscripts and the final published papers. A previous study examined the effect of requesting a copy of the title page of each cited article along with submitted manuscripts; ${ }^{9}$ the error rate was more than halved, from $48 \%$ to $22 \%$ between
1990 and 1994. The Journal of Bone and Joint Surgery [British] similarly requests copies of all cited papers not held in their own database, to allow careful checking.

The burgeoning orthopaedic literature puts pressure upon the reader, ${ }^{0,11}$ and inaccuracies will only reduce the impact of a paper. We found a low level of error in the samples of the two volumes of the Journal of Bone and Joint Surgery, a marked improvement in the number of errors in Acta Orthopaedica Scandinavica between 1985 and 1994, and persistently high levels of error in Clinical Orthopaedics and Related Research. Low levels of error reflect a high level of editorial commitment to accuracy and are to be commended.

No benefits in any form have been received or will be received from a commercial party related directly or indirectly to the subject of this article.

References

1. Cowell HR. Ethics of medical authorship. J Bone Joint Surg [Am] 1998;80-A:151-3.

2. Ngan Kee WD, Roach VJ, Lau TK. How accurate are references in the Australian and New Zealand Journal of Surgery? Aust NZ J Surg 1997;67:417-9.

3. Evans JT, Nadjari HI, Burchell SA. Quotational and reference accuracy in surgical journals: a continuing peer review problem. JAMA 1990;263:1353-4.

4. McLellan MF, Case LD, Barnett MC. Trust, but verify: the accuracy of references in four anaesthesia journals. Anesthesiology 1992;77:185-8.

5. Roach VJ, Lau TK, Kee WD. The quality of citations in major international obstetrics and gynecology journals. Am J Obstet Gynecol 1997; 177:973-5.

6. Orlin W, Pehling J, Pogrel MA. Do authors check their references? a survey of 500 references from the Journal of Oral and Maxillofacial Surgery. J Oral Maxillofac Surg 1996;54:200-2.

7. Hansen ME, McIntire DD. Reference citations in radiology: accuracy and appropriateness of use in two major journals. AJR Am J Roentgenol 1994;163:719-23.

8. Due S. How accurate are references in the Australian and New Zealand Journal of Surgery? Comment. Aust NZ J Surg 1998;68:236.

9. Asano M, Mikawa K, Nishina K, Mackawa N, Obara H. Improvement of the accuracy of references in the Canadian Journal of Anaesthesia. Can J Anaesth 1995;42:370-2.

10. Dandy DJ. Orthopaedic information: a superglut? J Bone Joint Surg [Br] 1996;78-B:3-4.

11. Moir JS, Sutherland AG, Maffulli N. International orthopaedic journals: a 15-year review. J Bone Joint Surg [Br] 1998;80-B:6-7. 